\title{
Survey Based Study on Stress Level and Sleep Quality among Hostelers
}

\author{
Ambreen Fatima ${ }^{1}$, Mangalam Kumari ${ }^{1}$, Arman Jahan ${ }^{2}$, \\ Pramod Kumar Sahu ${ }^{1}$, Pooja Kukreti ${ }^{1}$, Monika Sharma ${ }^{1}$ \\ ${ }^{1}$ Assistant Professor, Galgotias University, Greater Noida India, \\ ${ }^{2}$ Student Researcher, BPT Galgotias University, Greater Noida, India
}

\begin{abstract}
Objective: The aim of this study is to evaluate the stress level and quality of sleep among hostelers using PSS \& PSQI scales.

Method: The current study is observational study. A sample of 272 subjects of both the genders between 18-28 years were recruited for the study. All the subjects has been explained the procedure and were asked to give their demographic data and to fill the stress and sleep questionnaire forms for the interpretation of the result.

Result: The google analyser was used to analyse the data and result shows that In this study after analysis of data we got that $50 \%$ of students are upset sometimes, $13.7 \%$ are not upset at all, $15.2 \%$ are fairly upset and $8.5 \%$ are very often. $45.9 \%$ students are in stress sometime in the month, $16.7 \%$ are fairly in stress, $12.2 \%$ are very stressed in last month. $44.4 \%$ students are sometimes irritated in the last month and 13.3 are very irritated in last month. $84.4 \%$ of students have not taken any medicine for sleeping at night but rest had taken medicine to sleep at night once, twice, or thrice a week. $71.1 \%$ students don't have any issue while awake at night due to driving/eating or social activity rest $29.1 \%$ have an issue while awaking at night. $50.4 \%$ students say their sleep quality is fairly good in last month, $19.3 \%$ says fairly bad, 4.7 says very bad and $25.6 \%$ don't have any issue in sleeping.
\end{abstract}

Conclusion: It was concluded that there is less stress present in the students of hostel and also only some students were found with the bad quality of sleep

Keywords: Hostellers, Stress, Sleep, Sleep Quality, PSS.

\section{Introduction}

"Environment of the home and the role of the family members play an important role in the development of the children. Differences of the factors such as the socioeconomic status of the family, educational difference, biological endowment starts making enduring differences in the development children behaviours,

\footnotetext{
Corresponding Author:

Ambreen Fatima

Assistant Professor (Galgotias University), Kriti Nagar, Delhi

e-mail: ambreen.fatima@galgotiasuniversity.edu.in
}

changes the personality of the children. Surroundings of a children residential area also affect socialization process. A expand or limit of educational opportunities of the children can be seen as a result ${ }^{1,2}$. Hostel life is living away from home in another place all the educational institutes usually have their hostels. Whole environment becomes so different of the hostel to the environment of the home, as some rules can be so strict that students may not enjoy living in the hostel. Here students have to come up with all the problems by themselves. Any of these factors may become the reason of one's stress and may have impact on one's sleep quality. All these problems may induce deviant behaviours or may cause psychological problems further ${ }^{3}$. Stress is a psychological response to the threat perceived by the 
person ${ }^{4}$. Numerous readjustments that requires in any changes of life can be perceived as stressful ${ }^{5}$. Physical, social, emotional and family problems of these students may affect their academic performance and ability of learning ${ }^{6,7}$. When pressure crosses its perceived ability to cope with problems than the pressure occurs ${ }^{3}$. "Stress is a complex, multidimensional negative emotion" defined by ${ }^{8,9}$ defined stress is directly relates to features of psychology such as relaxation, broadening, reframing and creativity. A specific and crucial role sleep plays in consolidation of the memory ${ }^{10,11,12}$. Also lack of sleep may results in poor cognition and attention. Lack of sleep along with the worsening of cognition also increases the sleepiness and fatigue ${ }^{10,13,14,15,16}$. A study shows that the person who has been awake for $17 \mathrm{~h}$ his cognition function would be equivalent to the person whose concentration of blood alcohol is $0.05 \%{ }^{10,17}$. In general, academic performances in school are associated with sleep. Lack of sleep may lead to poor attention and concentration during the class ${ }^{18}$. Most of the studies show that the better and longer sleep quality is linked to the better academic performances such as more efforts towards the study or getting better grades in the exams ${ }^{19-27}$ The purpose of this study is to evaluate the stress level and sleep quality among the hostellers. This study will help us to determine the level of stress and quality of sleep among the hostellers.

\section{Methodology}

\section{Study Design: Observational}

Sample selection criteria: 272 normal, healthy hostel students will be taken, aged between (17-30) years. The subjects will be taken randomly from the colleges and universities. Subjects will be given a questionnaire-based forms for the collection.

\section{Sampling Method:}

Randomized selection of the subjects

Sample of the convenience

No. of sample: 270 hostel students

\section{Questionnaires used for the study:}

1. Stress level (PSS-Perceived Stress Scale) questionnaire.

2. Sleep quality (PSQI-Pittsburgh Sleep Quality Index) questionnaire.

\section{Inclusion Criteria:}

1. Hosteller

2. Age: (17-30)

Both male and female

\section{Exclusion criteria:}

1. Devoid of any psychosomatic disorder

Procedure: The participants volunteered to participate in the study were all guaranteed about the confidential nature of the study. All the participants were informed that their participation in this study is fully voluntary and they may withdraw themselves at any time and informed that this if fully academic study. After fulfilling the subject's inclusion and exclusion criteria and given explanation about the study. The subject demographic data was collected. Subjects were explained the PSS and PSQI and then asked to fill these questionnaire-based form for the data collection. On the basis of result obtained the stress level and sleep quality will be evaluated among the hostellers.

All subjects were undergone demographic assessment first and then asked to fill the questionnaire on the stress level and sleep quality. Data collected from the subjects was recorded and analysed by using the Google Analyser. Readings were used to interpret the result of the stress level and sleep quality among the hostellers in the form graphs and charts. All the required data was collected by the researcher. Manual entry of the data was done on a pre- planned format. The individual record of each subjects was noted in the his/her own form.

Ethical Consideration: All the subjects were informed about the study objectives. No unnecessary harm was caused to subjects involved. No interference was done with the subject privacy. Subject personal details privacy was maintained.

\section{Results}

In this study after analysis of data we got that $50 \%$ of students are upset sometimes, $13.7 \%$ are not upset at all, $15.2 \%$ are fairly upset and $8.5 \%$ are very often. $45.9 \%$ students are in stress sometime in the month, $16.7 \%$ are fairly in stress, $12.2 \%$ are very stressed in last month. $44.4 \%$ students are sometimes irritated in the last 
month and 13.3 are very irritated in last month. $84.4 \%$ of students have not taken any medicine for sleeping at night but rest had taken medicine to sleep at night once, twice, or thrice a week. $71.1 \%$ students don't have any issue while awake at night due to driving/eating or social activity rest $29.1 \%$ have an issue while awaking at night.
$50.4 \%$ students say their sleep quality is fairly good in last month, $19.3 \%$ says fairly bad, 4.7 says very bad and $25.6 \%$ don't have any issue in sleeping. So by this data, we can say that the many students are having stress and their mental health is not in good condition.

\section{Graphs:}

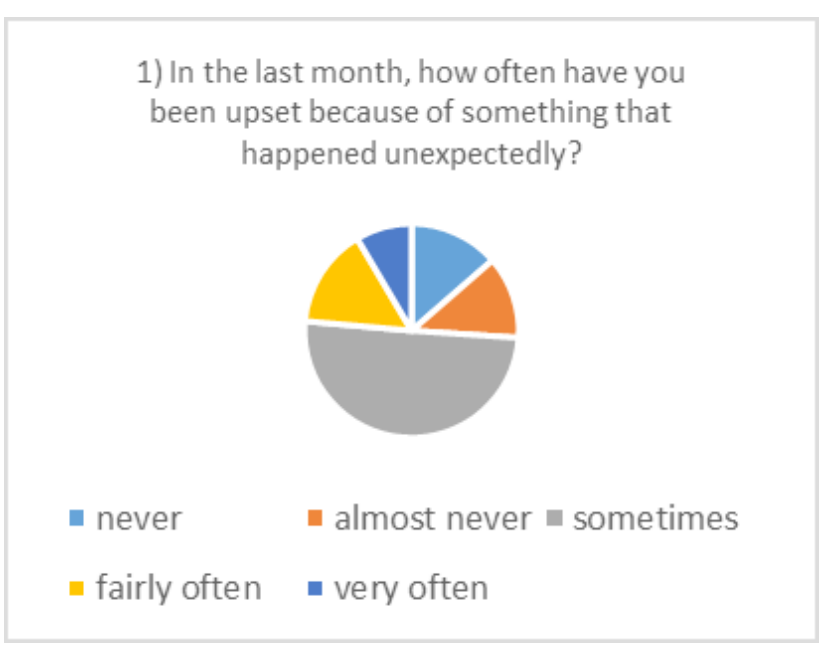

3) In the last month, how often have you felt that you were unable to control the important thigs in your life?

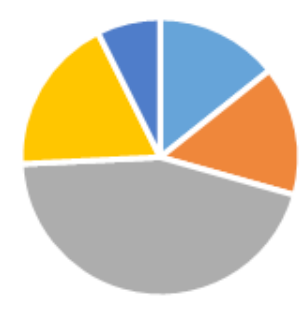

$$
\begin{aligned}
& \text { - never } \quad \text { almost never }=\text { sometimes } \\
& \text { m fairly often } \quad \text { - very often }
\end{aligned}
$$

5) In the last month, how often have you felt that things were going your way?

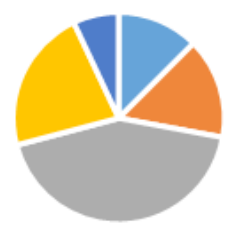

$$
\begin{aligned}
& \text { - never } \quad \text { - almost never }=\text { sometimes } \\
& \text { - fairly often } \quad \text { - very often }
\end{aligned}
$$

\section{2) In the last month, how often have you felt nervous and "stressed"?}

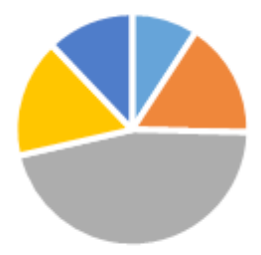

$$
\begin{aligned}
& \text { never } \quad \text { almost never } \text { - sometimes } \\
& \text { m fairly often } \quad \text { very often }
\end{aligned}
$$

4) In the last month, how often have you felt confident about your ability to handle your personal problems?

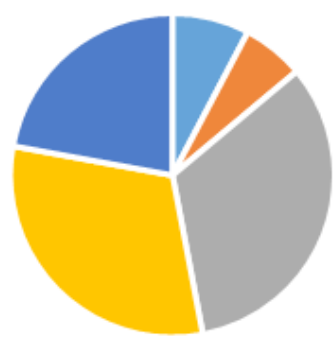

$$
\begin{aligned}
& \text { - never } \quad \text { - almost never } \text { - sometimes } \\
& \text { = fairly often } \quad \text { - very often }
\end{aligned}
$$

6) In the last month, how often have you found out that you could not cope with all the things you had to do?

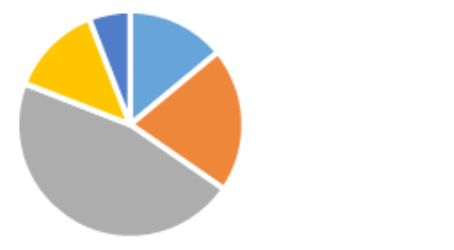

$$
\begin{aligned}
& \text { - never } \quad \text { almost never }=\text { sometimes } \\
& \text { m fairly often } \quad \text { very often }
\end{aligned}
$$




\section{Discussion}

The purpose of this study was to evaluate the stress level and sleep quality among the hostellers. The study was designed to determine whether there is any stress level and to evaluate the quality of sleep among the hostellers. The previous studies have shown the quality of life, mental health status, mobile usage among the hostel students etc. The stress level and sleep quality are yet been not checked among the hostellers unlike in the different courses of college or university students, so the current study was taken to evaluate the stress level and quality of sleep by using questionnaire among the students of the hostel.

In the current study the result nearly $50 \%$ of the students shows low stress level, moderate to severe stress level observed among about $23.7 \%$ students and on the other hand $13.7 \%$ students shows no stress at all. In a study of Vivek B. et al in Sultan Qaboos University, Maharashtra, India, stress was present in $24.4 \%$ students of the university, in which moderate to severe stress was observed in $14.4 \%$ of the respondents ${ }^{30} \mathrm{In}$ another study of Mumbai medical students, Supe et al found out $73 \%$ students had perceived stress ${ }^{31}$. AbuGhazaleh et al, observed in Jordan, on dental students that stress present among the $70 \%$ of the students ${ }^{32}$. In addition, it is also necessary to note that ${ }^{30}$ applied the scale was DASS-21, measures stress. In the study ${ }^{31}$ used the perceived stress for the subjects and ${ }^{32}$ considered a 12-item general health questionnaire (GHQ-12) that measures the psychiatric morbidity. Whereas in present study the Perceived Stress Scale was used to evaluate the stress level among the hostelers. Supe et al in 1998 noticed that stress was respective of the class and semester of the students whereas irrespective of the present accommodation of those students. On the other hand vivek ${ }^{30}$ et al observed that stress had no association with class and semester, the present accommodation proved as a highly important feature, they concluded that students living in the hostel becomes more sensitive and prone to stress. Might be due to reason that students found hostel condition quite unsatisfactory as they come from a very comfortable place 'home', that results into reason for great stress among hostelers. AbuGhazaleh also researched about the significance of the variant factors of academics. Another researcher Barikani et $\mathrm{al}^{33}$ determined probability that among the medical students of Iran the residence and the finance associated problems were proved as stressors among the students. Harshini ${ }^{34}$ et al in 2015 conducted a study to measure the stress in the hostellers and the day scholars, he used a PSS (Perceived Stress Scale) to determine the result and observed that stress was present in the both the groups as hostellers, when they come to hostel's very new environment from their comfortable homes and their parents' supportive hands it becomes quite difficult to them to mould themselves according to new place and people that might leads to separation stress. He concluded in the study that statistically the day scholars had more stress comparatively to the hostelers, as according to him day scholars have laxity of time for the fulfilment of study tasks and also interactions to their friends as they can only meet them during college hours due to their exhausted travelling time.

\section{Limitation of the study:}

- One of the limitations of this study the result was not based on any factors like gender, socioeconomic, environment.

- The study was limited to some geographical boundaries.

- Factors such as current status of person's personality or emotions might be present.

- And also, the different time spans of the students such as the period of examination, pre-examination, or post-examination were not included in the study.

\section{Future Studies:}

- Future studies could evaluate pre and post exam stress level as well as quality sleep among the hostelers.

- There could be a comparison done of stress level and quality of sleep between males and females hostelers.

- There could also be a comparison between sleep quality and stress level among the different year hostel students such as first, second, third, and fourth year.

\section{Conclusion}

The current study is dealt with the stress level and quality of sleep among hostelers. The result of the study shows that there is almost no effect on the sleep quality 
of the hostellers. The evaluated data show a very less effect on the stress level of the hostelers.

\section{Funding Sources: Self}

\section{Conflict of Interest: NA}

\section{References}

1. Fergusson DM, Horwood LJ, Boden JM. The transmission of social inequality: Examination of the linkages between family socioeconomic status in childhood and educational achievement in young adulthood. Research in Social Stratification and Mobility. 2008 Sep 1;26(3):277-95.

2. Tucker $\mathrm{P}$, van Zandvoort MM, Burke SM, Irwin JD. The influence of parents and the home environment on preschoolers' physical activity behaviours: A qualitative investigation of childcare providers' perspectives. BMC public health. 2011 Dec;11(1):1-7.

3. Kumar S, Bhukar JP. Stress level and coping strategies of college students. Journal of Physical Education and Sport Management. 2013 Jan 31;4(1):5-11.

4. Pinel JPT (2003), Biopsychology ( $5^{\text {th }}$ edition). United States of America: Allyn and Bacon. Roy AM. Coursework stress in University students.

5. Bramwell ST, Masuda M, Wagner NN, Holmes TH. Psychosocial factors in athletic injuries: development and application of the social and athletic readjustment rating scale (SARRS). Journal of human stress. 1975 Jun 1;1(2):6-20.

6. Fish C, Nies (formerly Albrecht) MA. Health promotion needs of students in a college environment. Public Health Nursing. 1996 Apr;13(2):104-11.

7. Chew-Graham CA, Rogers A, Yassin N. 'I wouldn't want it on my CV or their records': medical students' experiences of help-seeking for mental health problems. Medical education. 2003 Oct;37(10):873-80.

8. Lazarus RS. Toward better research on stress and coping.

9. Caulfield N, Chang D, Dollard MF, Elshaug C. A Review of Occupational Stress Interventions in Australia. International Journal of stress management. 2004 May;11(2):149.

10. Okano K, Kaczmarzyk JR, Dave N, Gabrieli
JD, Grossman JC. Sleep quality, duration, and consistency are associated with better academic performance in college students. NPJ science of learning. 2019 Oct 1;4(1):1-5.

11. Walker MP, Stickgold R. Sleep, memory, and plasticity. Annu. Rev. Psychol.. 2006 Jan 10;57:139-66.

12. Rasch B, Born J. About sleep's role in memory. Physiological reviews. 2013 Apr 1.

13. Lim J, Dinges DF. A meta-analysis of the impact of short-term sleep deprivation on cognitive variables. Psychological bulletin. 2010 May;136(3):375.

14. Harrison Y, Horne JA. The impact of sleep deprivation on decision making: a review. Journal of experimental psychology: Applied. 2000 Sep;6(3):236.

15. Alhola P, Polo-Kantola P. Sleep deprivation: Impact on cognitive performance. Neuropsychiatric disease and treatment. 2007.

16. Durmer JS, Dinges DF. Neurocognitive consequences of sleep deprivation. Seminars in neurology. Vol.

17. DawsonD, ReidK. Fatigue, alcohol and performance impairment. Nature. 1997 Jul;388(6639):235-.

18. Orzech KM, Salafsky DB, Hamilton LA. The state of sleep among college students at a large public university. Journal of American College Health. 2011 Aug 1;59(7):612-9.

19. Wagner U, Gais S, Haider H, Verleger R, Born J. Sleep inspires insight. Nature. 2004 Jan;427(6972):352-5.

20. Wong ML, Lau EY, Wan JH, Cheung SF, Hui CH, Mok DS. The interplay between sleep and mood in predicting academic functioning, physical health and psychological health: A longitudinal study. Journal of psychosomatic research. 2013 Apr 1;74(4):271-7.

21. Eliasson AH, Lettieri CJ, Eliasson AH. Early to bed, early to rise! Sleep habits and academic performance in college students. Sleep and Breathing. 2010 Feb 1;14(1):71-5.

22. Gaultney JF. The prevalence of sleep disorders in college students: impact on academic performance. Journal of American College Health. 2010 Sep 23;59(2):91-7.

23. Gilbert SP, Weaver CC. Sleep quality and academic performance in university students: A wake-up call 
for college psychologists. Journal of college student psychotherapy. 2010 Sep 27;24(4):295-306.

24. Gomes AA, Tavares J, de Azevedo MH. Sleep and academic performance in undergraduates: a multimeasure, multi-predictor approach. Chronobiology International. 2011 Nov 1;28(9):786-801.

25. Lemma S, Berhane $\mathrm{Y}$, Worku A, Gelaye B, Williams MA. Good quality sleep is associated with better academic performance among university students in Ethiopia. Sleep and Breathing. 2014 May 1;18(2):257-63.

26. Merikanto I, Lahti T, Puusniekka R, Partonen T. Late bedtimes weaken school performance and predispose adolescents to health hazards. Sleep medicine. 2013 Nov 1;14(11):1105-11.

27. Mirghani HO, Mohammed OS, Almurtadha YM, Ahmed MS. Good sleep quality is associated with better academic performance among Sudanese medical students. BMC research notes. 2015 Dec;8(1):1-5.

28. Abebe AM, Kebede YG, Mengistu F. Prevalence of stress and associated factors among regular students at Debre Birhan governmental and nongovernmental health science colleges North
Showa zone, Amhara region, Ethiopia 2016. Psychiatry journal. 2018 Jan 1;2018.

29. Scott E. Stress in college, Common causes of stress in college. Health Promotion International Journal. 2009;2(16):215-32.

30. Waghachavare VB, Dhumale GB, Kadam YR, Gore AD. A Study of Stress among Students of Professional Colleges from an Urban area in India. Sultan Qaboos University Medical Journal. 2013 Aug;13(3):429.

31. Supe AN. A study of stress in medical students at Seth GS Medical College. Journal of postgraduate medicine. 1998 Jan 1;44(1):1.

32. Psychological stress among dental students at the University of Jordan. Journal of dental education. 2011 Aug;75(8):1107-14.

33. Saeed AA, Bahnassy AA, Al-Hamdan NA, Almudhaibery FS, Alyahya AZ. Perceived stress and associated factors among medical students. Journal of family \& community medicine. 2016 Sep;23(3): 166.

34. Ravichandran H. Measuring stress in hostelites and day scholars. Research Journal of Pharmacy and Technology. 2015;8(6):710-2. 